\title{
ON THE USE OF \\ PROTON BEAMS FOR RADIOTHERAPY: \\ A SUMMER STUDY AT ORIC
}

J. G. Castle, Jr.

R. B. Dickinson

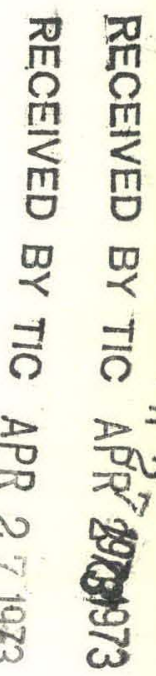




\section{DISCLAIMER}

This report was prepared as an account of work sponsored by an agency of the United States Government. Neither the United States Government nor any agency Thereof, nor any of their employees, makes any warranty, express or implied, or assumes any legal liability or responsibility for the accuracy, completeness, or usefulness of any information, apparatus, product, or process disclosed, or represents that its use would not infringe privately owned rights. Reference herein to any specific commercial product, process, or service by trade name, trademark, manufacturer, or otherwise does not necessarily constitute or imply its endorsement, recommendation, or favoring by the United States Government or any agency thereof. The views and opinions of authors expressed herein do not necessarily state or reflect those of the United States Government or any agency thereof. 


\section{DISCLAIMER}

Portions of this document may be illegible in electronic image products. Images are produced from the best available original document. 
This report was prepared as an account of work sponsored by the United States Government. Neither the United States nor the United States Atomic Energy Commission, nor any of their employees, nor any of their contractors, subcontractors, or their employees, makes any warranty, express or implied, or assumes any legal liability or responsibility for the accuracy, completeness or usefulness of any information, apparatus, product or process disclosed, or represents that its use would not infringe privately owned rights. 
Contract No. W-7405-eng-26

Physics Division

ON THE USE OF PROTON BEAMS FOR RADIOTHERAPY:

A SUMMER STUDY AT ORIC

J. G. Castle, Jr. and R. B. Dickinson

APRIL 1973

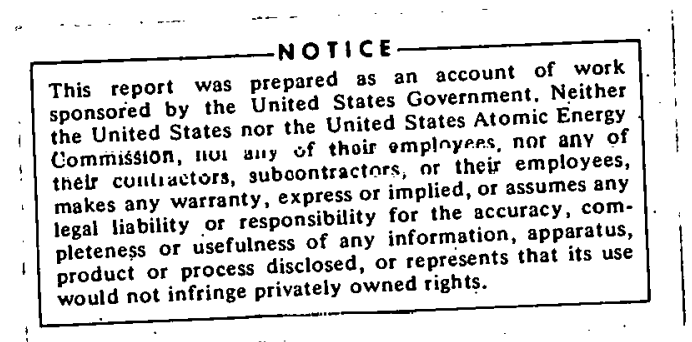

OAK RIDGE NATIONAL LABORATORY

Oak Ridge, Tennessee 37830

Operated by

UNION CARBIDE CORPORATION

for the

U. S. ATOMIC ENERGY COMMISSION

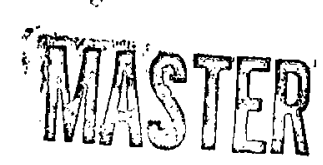


THIS PAGE

\section{WAS INTENTIONALLY LEFT BLANK}


CONTENTS

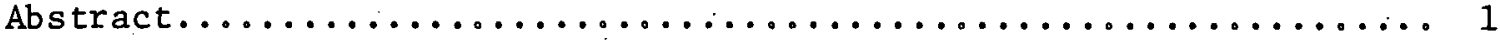

The Rationale of Radiotherapy....................... 1

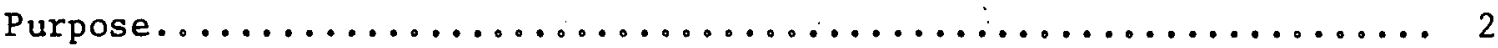

The Characteristics of Proton Beams of Interest for Cancer Therapy.. 2

Dose Distributions Attainable with the $65 \mathrm{MeV}$ Protons of the ORIC... 3 Uniformity Transverse to the Beam.................... 4 Isodose Contours for Treating Carcinoma of the Tonsil........ 4

Isodose Contours for Treating Carcinoma of the Inner Ear...... 5

Dose Distributions Available with More Energetic Protons......... 5 5 Isodose Contours for Pituitary Irradiations.............. 5 Uniformity Transverse to the Beam..................... 5 Isodose Contours for an Abdominal Target ............... 6

Elements of Patient Treatment with Fast Protons............. 7

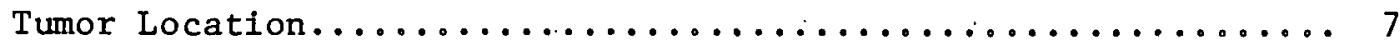

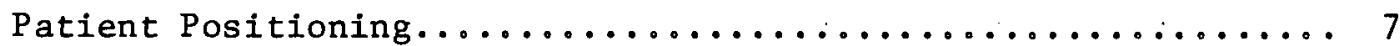

Dosimetry on the Patient.......................... 8

Dosimetry on the Beam......................... 8

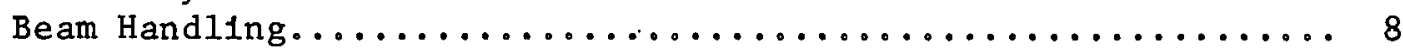

Sources of Protons with Resident Radiotherapist............ 9

Patients..................................... 9

A Choice of the UAB Radiotherapy Department................... 10

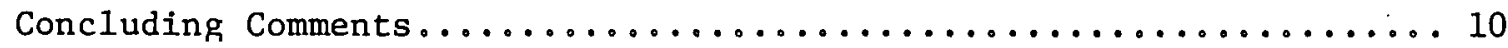

Acknowledgements $\ldots \ldots \ldots \ldots \ldots \ldots \ldots \ldots \ldots \ldots \ldots \ldots \ldots \ldots \ldots$ 
ON THE USE OF PROTON BEAMS FOR RADIOTHERAPY:

A SUMMER STUDY AT ORIC

J. G. Castle, Jr. ${ }^{*}$ and R. B. Dịckinson ${ }^{\dagger}$

\begin{abstract}
Practicing radiotherapists have recently shown an increased interest in using the improved dose distributions available with fast proton beams. Discussions involve the criteria for and mechanics of a pilot study for cancer therapy at an existing proton facility. Dose distributions available with $65 \mathrm{MeV}$ (ORIC) and with $130 \mathrm{MeV}$ (Harvard-Mass. General, BNL, and NAL) are calculated and the computer printouts displayed. Reasons against using the ORIC are dis-. cussed. Use of protons with range greater than $10 \mathrm{~cm}$ for pilot study is planned.
\end{abstract}

\title{
THE RATIONALE OF RADIOTHERAPY
}

A malignant tumor is a collection of rapidly growing (malignant) cells usually intermingled with a comparable density of normal cells. Effective radiotherapy for cancer patients relies on early detection ${ }^{1}, 2$ of tumor masses and on the ability of the normal tissue - internal and nearby - to recover from the irradiations of the tumor target region to dose levels that reduce the survival of the malignant cells below 1 cell in $10^{9}$ original cells. ${ }^{3}$ Since there is no convincing evidence that malignant cells are or can be made more radiosensitive than normal ones, reliance in therapy is placed on preferential recovery of the normal tissue, which occurs through cooperative body mechanisms involving the migration of cells into the heavily irradiated region. This recovery is a complicated"function of dose schedule - dose delivered during each exposure and time between exposures, of dose distribution, of tissue types involved, and, of course, of the stage of the disease. The clinical significance of the so-called high LET types of radiation, such as negative pions and very heavy ions, that kill cells by processes independent of the oxygen level; is not yet.clear but is now under study. 4-7. For low LET radiations, such as $x$-rays and protons, the clinical significance of steeper gradients in the dose distributions is

*Consultant to ORNL and Clinical Professor of Therapeutic Radiology, University of Alabama - Birmingham Medical Center.

tORAU Summer Student; Department of Physics, University of California, Berkeley. 
uncertain as yet; but its promise is the basis of recently increased interest on the part of practicing radiotherapists to use protons for therapy trials.

The difficulty of selecting an appropriate tumor target dose level without overdoing it with the normal tissues is indicated by the sigmoid shaped curves of Fig. 1. The statistics of the data used by Boone and Wiley 8,9 indicate differential responses to irradiation by $\gamma$-rays from ${ }^{60}$ Co with $75 \%$ controlled and $25 \%$ complications near 6000 rads but on $1 y$ about $25 \%$ controlled tumors near 5000 rads total dose. It is also obvious from Fig. I why a dose as 10 as $50 \%$ is of ten neglected, except for radiosensitive tissues.

\section{PURPOSE}

The purpose of this note is to report an exploration of the basis for the radiotherapists' interest in proton therapy trials and of the extent to which their interest can be converted into action. We show the conversion of proton beams characteristics into isodose contours for several tumor types. The criteria for carrying out trials are discussed and the reaction of one group of radiotherapists is indicated.

\section{THE CHARACTERISTICS OF PROTON BEAMS OF INTEREST FOR CANCER THERAPY}

Fast protons deposit energy in water primarily by ionization at low rates of energy transfer (LET), i.e., LET below $5 \mathrm{keV} / \mu \mathrm{m}$. Since the probability for making an ion pair out of a neutral molecule increases as the proton's velocity derreases, the proton's linear enorgy transfer (LET) increases as the proton slows and each proton is likely to deliver its last $100 \mathrm{keV}$ of kinetic energy within one or two cell. diameters of the end of its track. This $100 \mathrm{keV}$ is 1 ess than $0.5 \%$ of the energy this proton deposits in its last $\mathrm{cm}$. However, when a beam of protons passes through tissue, the differences in the collisions between the tissue molecules and the different protons within the beam produces range straggle of several percent of the initial range. After passage through several centimeters of tissue, the range straggle of a millimeter or more reduces the peak value of the average LET delivered by the protons in the beam to a value below $4 \mathrm{keV} / \mathrm{\mu m}$. The first evidence for this peak was reported 10 by Bragg in 1904. More recent measurements have been described by $A$. Koehler ${ }^{1}$ showing the height of the Bragg-peak for $130 \mathrm{MeV}$ protons to be $1.8 \mathrm{keV} / \mu \mathrm{m}$. So, except for that negligibly small fraction of the deposited energy delivered in sizable chunks to a few cells, the effects of a dose delivered by protons is expected to be biologically equivalent to the same size dose delivered by $x$-rays.

This equivalence between proton and $x-r$ ay dose has been verified in a number of biological systems, with the studies that have the better 
statistics giving the values closer to unity for the relative biological effectiveness for protons.12,13 The equivalence is considered an advantage by radiotherapists because the normal recovery processes can be relied on and the first treatment plan can be identical to those now in use with $\mathrm{x}$-rays; this permits a rather direct comparison of the effects of the improved dose distributions avallable with multi-port irradiation by fast protons.

The use of the Bragg-peak to concentrate the dose from protons in tumor targets was first suggested ${ }^{14}$ by Wilson in 1946. A wide beam of $130 \mathrm{MeV}$ protons offers about three times the dose level at the $12 \mathrm{~cm}$ depth of the unmodified Bragg-peak as at the entry port, and a falloff to $40 \%$ of the peak at $4 \mathrm{~mm}$ beyond the peak. Spreading or modification of the Bragg-peak to cover the tumor thickness with a uniform, dose.sti11 permits sharp falloff outside the target area and low entering dose with multiple entry ports. We shall see, for example, that a tumor thickness of $25 \%$ of the initial range of the protons can be covered from two ports opposed and have falloff to $33 \%$ at the skin and to $60 \%$ at $6 \mathrm{~mm}$ from the edges of the target (100\%) region. The experience of the past few decades of getting considerable improvements in cure rates from radiotherapy as the dose distributions were improved from $250 \mathrm{kVp} x$-rays through cobalt 60 to megavoltage $x$-rays is the intuitive bas is for the recent interest in therapy trials with the further improvements in dose distributions available with protons.

The question remained, therefore, to find out whether there was enough interest in the available beams of $65 \mathrm{MeV}$ protons at the ORIC and the $130 \mathrm{MeV}$ protons at Harvard to get trials started. The procedure we used was to generate isodose contours on the anatomical maps supplied by the UAB therapists for several candidate cases. The isodose printouts from the computer were then used as a basis for treatment planning and then, if appropriate, for the financial and technical planning of the proton trials.

DOSE DISTRIBUTIONS ATTAINABLE WITH THE $65 \mathrm{MeV}$ PROTONS OF THE ORIC

The tumor types within reach of the $35 \mathrm{~mm}$ range of the ORIC protons include several of the head and neck region. The target dimensions transverse to the beam direction in the single entry port are typically a couple of inches across. The depth vs. dose delivered for wide beams of $65 \mathrm{MeV}$ protons, as listed in Table I, takes into account the few percent of proton absorption found ${ }^{11}$ for passage through $35 \mathrm{~mm}$ of water. The unmodified Bragg-peak of the ORIC beam is four times the entering dose. 


\section{Uniformity Transverse to the Beam Direction}

The method of covering the tumor target field transverse to the beam direction at the ORIC ${ }^{5}$ is to expand the normally small beam to a lateral extent many times larger than the target size and then mask off the edges. One example of the uniformity of proton flux to be obtained at the ORIC is shown in Fig. 2. Bender's measurements ${ }^{16}$ indicate the isodose contours are approximately circles and the diameters for the $98 \%$ and $96 \%$ contours were made as large as six inches and ten inches, respectively.

The masking procedure is quite consistent with the low beam currents desired for proton radiotherapy. To fit the normal dose schedule for teletherapy involving 200 to 300 rads per exposure, a $60 \mathrm{gm}$ tumor target would require some 13 to 20 bilition protons or 0.1 nanoampere for 20 to 30 seconds delivered uniformly over the target volume.

\section{Isodose Contours for Treating Carcinoma of the Tonsil}

Palliation of carcinoma of the tonsil has been carried out with teletherapy using the dose distribution plotted in the upper part of Fig. 3 where the 140 contour was given the target dose. For the comparison to protons, we modified 17,18 the Bragg-peak as listed in Table I to obtain uniform target dose over $25 \mathrm{~mm}$ thickness and the resulting dose distribution is sketched in the lower portion of Fig. 3.

As a way of demonstrating the role of digital computers in proton radiotherapy, we developed a computer program, called FIRST, which takes as inputs: (a) the anatomical map of the body cross-section under consideration, (b) the depth vs. dose of the entering particle such as the listing in Table I for $65 \mathrm{MeV}$ protons, (c) the beam edges, and, (d) the number and size of the steps in an energy absorber used to spread out the Bragg-peak over the tumor thickness. The output of FIRST is then printed as a full scale ( $1: 1)$ map of the body section overlaid with the isodose contours. An example for the tonsil tumor case is shown in Fig. 4, where the computer printout of the head section at about one $\mathrm{cm}$ above the lower edge of the mandible labels the skin by the letter $S$, bone by 0 , the tumor "edges" by $X$ and the isodose contours by integers. The $9^{\prime}$ 's represent the highest dose level, where the uniformity inside that contour depends on how many steps are made in the rotating blade absorber; the $0^{\prime}$ 's represent less than $5 \%$; and the small dose (estimated at about $5 \%$ ) due to neutrons 19,20 has been ignored. Additional information labels are supplied in Fig. 4 as typical of the convenience available in computer printout, including such items as:

1. the midline of the body section,

2. identification of the case and a record of selected details, and

3. tick marks spaced 2 inches around the boundaxy.

More anatomical information would have been printed out in this figure if it had been included in the input. An example of more complete anatomical outlines from ultrasound is printed out by the computer in a later figure. 
The isodose contours calculated and printed out by computer, as shown in Fig. 4, correspond to the ones hand drawn in Fig. 3 for $65 \mathrm{MeV}$ protons showing a falloff to $10 \%$ in about $4 \mathrm{~mm}$ beyond the target edge.

\section{Isodose Contours for Treating Carcinoma of the Inner Ear}

The $35 \mathrm{~mm}$ range of the $65 \mathrm{MeV}$ protons of the ORIC is sufficient to cover the target regions for a typical case of carcinoma of the inner ear. The printout of the isodose contours obtainable is shown in Fig. 5, where in an actual case a plastic or wax cast of the outer ear configuration would be used to control the depth of the far edge of the beam. A similar falloff to a $10 \%$ dose would be obtained at about $4 \mathrm{~mm}$ farther on, and about $80 \%$ would be delivered to the skin.

\section{DOSE DISTRIBUTIONS AVAILABLE WITH MORE ENERGETIC PROTONS}

Protons are accelerated to kinetic energies of $160 \mathrm{MeV}$ by the Harvard-Massachusetts General Cyclotron and to $200 \mathrm{MeV}$ by the injector linacs at BNL and NAL. We chose the depth-dose characteristics of $130 \mathrm{MeV}$, as reported ${ }^{2 l}$, by Preston and Koehler and listed in Table II with a resolution of one $\mathrm{mm}$ depth in water, as the basis for generating a sample isodose plot for an abdominal tumor target. First, a comment is in order on the highly accurate dose distributions being used ${ }^{11,17}$ for pituitary irradiations at Harvard.

\section{Isodose Contours for Pituitary Irradiations}

The current practicell of pituitary irradiations represents a high degree of reliability in delivering a sharply defined proton Bragg-peak dose to a sma11, deeply imbedded target. The accuracy of locating the $100 \%$ contour to within a fraction of a $\mathrm{mm}$, and thereby effectively sparing the eye nerves a few $\mathrm{mm}$ away, represents a successful application of a series of practical correction procedures, but is much higher accuracy than normally required for tumor irradiation in other locations within the body. For example, the calculations of Jannili for the proton LET in a variety. of materials and the measurements 11 at Harvard permit confidence in the correction of the contour location after proton passage through a known thickness of bone as being equivalent to passage through a corresponding thickness of muscle or water. Koehler also cited his radiographic technique for detecting a few tenths of a percent change in density along the proton beam as useful in developing accurate phantoms.

Uniformity Transverse to the Beam

The Harvard proton beam has been successfully expanded and then masked down to give a uniform flux of protons across the target area. 
The technique is similar to that used at the ORIC and described in Reference 15. The proton flux falls off slowly to approximately $90 \%$ of the axial value at $14 \mathrm{~cm}$ from the axis, 17 so a target field $5 \mathrm{~cm}$ across has flux of $98+\%$ at its edges.

\section{Isodose Contours for an Abdominal Target}

Location of certain abdominal tumors by means of sonar mapping has been successfully demonstrated by $D$. Brascho ${ }^{2}$ and is expected to become one of the principal means of monitoring the location of body tissues, including the tumor edges, while the patient is in position for proton beam exposure. Practical resolution of edges to within a few $\mathrm{mm}$ by sonar operating near $2 \mathrm{MHz}$ is consistent with the expected assignment of target region boundaries and represents a considerable improvement over other location techniques.

For the purpose of demonstrating the appearance of the anatomical map of an abdominal cross-section and its overlaid isodose distributions, we generated photographically a $1: 1$ scale anatomical map from a sonar map made ${ }^{2}$ at one $\mathrm{cm}$ below the umbilical on a patient whose $\mathrm{Ga}$ scan indicated the likely presence of a tumor. We used this map as input for computer program FIRST to generate the printout in Fig. 6 . The tumor's posterior surface ( $X^{\prime} s$ ) lies within $4 \mathrm{~mm}$ of one kidney, marked with 0 's. Then as first approximation to the dose distribution that a therapist might consider for this tumor, we assumed the use of:

1. two entry ports opposed with beam edges as shown, and an initial range of $120 \mathrm{~mm}$;

2. a rotating blade of two thicknesses ( 8 and $20 \mathrm{~mm} \mathrm{H}_{2} \mathrm{O}$ equivalent; and

3. apprnpriate wan or plastic uuluses to locate the far edge of the modified Bragg-peaks as shown by the 9's along the anterior and posterior target surfaces.

The appearance of Fig. 6 raises the practical question of whether the computer printout at $1: 1$ is a useful base for treatment planning. If so, it is certainly inexpensive and convenient to use.

The isodose contours available with $130 \mathrm{MeV}$ protons through two ports opposed, as shown for the case of an abdominal tumor in the printout of Fig. 6, indicate skin dose at about 33\% and 1ateral spread to about $50 \%$ at $5 \mathrm{~mm}$ from the edge of the chosen target region. The cluse kidney would receive more than $50 \%$ to a depth of $8 \mathrm{~mm}$ from its anteriorsurface, and about $40 \%$ over the remainder of its volume. Clearly better sparing of the kidney can be easily arranged by adding a beam entry from the side, if desired. 


\section{ELEMENTS OF PATIENT TREATMENT WITH FAST PROTONS}

The irradiation of cancer patients has had a sufficient history from the pioneering work ${ }^{22}$ of Lawrence, Tobias, and others at Berkeley and the continuing therapy at Uppsala ${ }^{23}$ and Harvard 11 to give confidence to a program of therapy trials on a wider range of tumor types. The elements necessary for such a program are:

1. a source of patients with suitable tumors and a resident radiotherapist;

2. a source of protons of known and controlled energy and an associated hospital;

3. accurate beam handling for defining the location and intensity of the modified Bragg-peak to be accumulated through multiple entry ports;

4. dosimetry on the beam;

5. dosimetry on the patient;

6. patient positioning, and

7. tumor location information for the patient in the beamline position(s).

The definition of which elements are necessary will change as the number of patients to be treated per day increases and the state of the disease improves. Assuming the initial procedures involve the services of a resident radiotherapist at the accelerator facility and its associated hospital nearby, the patient load is likely to be limited to a few referrals per month until successful remissions are found. The following comments assume that the exposure of each patient will follow the dose schedule typical of current teletherapy and will initially take up to an hour or two of beam time for each day's exposure. Another assumption is the willingness to evolve improved dosimetry, if necessary, but to start with only those dosimetry elements judged to be essential. The above necessary elements of a program of therapy trials are discussed below, in reverse order.

Tumor location procedures are being improved at UAB Medical Center, as mentioned above, by a combination of $\mathrm{Ga}$ scan and sonar mapping. 25 It is expected that an essential part of the patient workup during proton therapy trials is sonar mapping with the patient in position just before and soon after the irradiation. This implies adaptable beam controls or control devices so as to trim the planned target region to fit more closely the actual tumor location. Eventually the on-line location monitor should be developed, probably from multichannel sonar or an acoustic holograph.

Patient positioning devices are needed to hold the tumor target region, specified by the radiotherapist from anatomical maps and tumor location information such as sonar and $\mathrm{Ga}$ scan coincidence, in the beam line for each of the ports and exposures specified on the patient's dose schedule to a precision of a few $\mathrm{mm}$. When the proton beams of the NAL 
and BNL linacs are brought out to treatment rooms, they will very likely have bending magnets to deliver both horizontal and vertical beams to the tumor target region of the treatment.rooms. The present facilities at Harvard have a fixed horizontal beam line.with a rotable chair for positioning targets in the head and neck region in the beamline and permitting rotation of the patient for multiple entry ports. Unfortunately the chair will not elevate to put abdominal targets in the beam line. The ORIC facilities offer several convenient horizontal beam lines at 48 inches from the floor. Provided beam currents can be maintained in the range of a nanoampere, exposure times are not expected to exceed a few minutes. With the delivery of a dose of only a few hundred rads at each exposure, it should be possible to leave shielding doors open, permitting thereby the use of such devices as adhesive tape for positioning the patient with respect to the chair or table support.

Dosimetry on the patient would start with the tumor location data and a tentative target region specification and proceed through whatever graphical displays are available to specifying the treatment plan in terms of dose distribution and dose schedule. Then one or more beam monitoring instruments, are recommended as the user's confirmation of the beam delivery. An ionization chamber, thin to the beam, but sensitive enough to indicate total charge transmission to about $1 \%$ in the range of one to ten nanocoulombs of protons should be operated for each exposure as a check on the ionization chamber that the accelerator will very likely be using to monitor total charge delivered and to signal the end of each exposure.

Dosimetry on the beam will eventually become normal elements of the internal control of every computer-controlled source operated as part of a radiotherapy facility, such as the one Uppsala is planning. llowever, in the beylunlng of the crials we are considering, the facility which supplies the protons should make measurements of total flux during each exposure and of lateral distribution and either the modified Braggpeak or the energy spread in the beam just before or just after. each therapy exposure or both. This would assure the patient and the resident radiotherap1st of the delivery of the requested dose and dose distribution. Presumably after sufficient experience with reliable delivery at a beam facility, the beam measurements would be relaxed somewhat. A suggested aim is that the values of total dose be accurate to within $\pm 2 \%$ and the dose contour location to $\pm 2 \mathrm{~mm}$.

Cyclotron beam handling for defining the intensity and location of the appropriate modified Bragg-peak on a repeated schedule of exposures, each involving an accumulation of dose accurate to $\pm 2 \%$ through multiple ports, should probably have the types of devices and operation found to be so successful on pituitary irradiations at Harvard. The apparatus has been described by Koehlerll and is very similar to that used by Bender for animal irradiations at the ORIC. ${ }^{15}$ Reliance is placed on the stability over time of the beam intensity and its spatial and energy distribution when it is expanded and then masked down by a long 
collimator to the desired lateral. shape and size. Range modulation averaged over single exposure times of many seconds is satisfactorily attained by inserting a rotating absorber blade at a narrow point of the beam upstream of the expanding quadrupole magnet. Examples of the precision obtainable in the uniformity of the dose across the modified Bragg-peak by forming the absorber blade from layers of plastic, each a few $\mathrm{mm}$ thick are shown in Tables I and II. Experimental confirmation of the dose uniformity over the-target volume such as shown in these tables is reported. 11,24

Presumably the beam handling equipment required for the linac beams can be simpler because of the ability to vary energy rapidly. However, the beam handling at Harvard appears to be more than adequate for the therapy trials under consideration.

Sources of protons which have available beams and are located within possible travel distance of UAB Medical Center are: The Oak Ridge Isochronous Cyclotron (65 MeV), the Texas A\&M Cyclotron (circa. $50 \mathrm{MeV}$, the LAMPF proton linac, and the Harvard-Massachusetts General Cyclotron (circa $160 \mathrm{MeV}$ ). It should not be surprising to see the LAMPF facility at Los Alamos make proton therapy available as soon as its "pion" treatment rooms are ready for operation. Similarly it seems reasonable to expect that any effective "war on cancer" will include the $200 \mathrm{MeV}$ proton rifles available at BNL, Long Island and NAL, Batavia, Illinois.

Choice among these sites involves consideration of the cost per patient of the normal set of ten to twenty exposures and of whether an arrangement can be worked out to permit referral and transportation of curable patients. Since the cost of beam time at the ORIC and Harvard are comparable and are not the major component of the total cost, the choice depends on selecting, transporting, and caring for the patients. Presumably the associated hospital facilities are comparable or will be more than adequate at each site. It has been suggested that a resident radiotherapist such as $M$. Kligerman has recently become for LAMPF, would decrease the cost per patient and increase considerably the number of curable patients treated. In any case the treatment costs may run as high as several thousand dollars per patient for the first year or so.

Patients with tumors suitable for treatment in a pilot study of proton therapy are hard to find. The BNL Summer Study of Proton Therapy dealt extensively with this selection problem. Some of the radiotherapists agreed that deep tumors in the abdominal region are suitable. Special interest has been placed on the type of tumor for which present cure rates are very low. For example, two radiotherapists: have independently suggested that the pilot study accept cases of pancreatic tumors and attempt to treat for cure. While the incidence rate is not high for tumors of the pancreas (located roughly as shown in Fig. 6 but in a higher body section), the cure rate is so low that patient referrals should be available from a wide population, probably enough to build up the peticnt load to several per week. 


\section{A CHOICE OF THE UAB RADIOTHERAPY DEPARTMENT}

After inspection of the improved dose distributions as printed in Fig. 4, 5, and 6, consideration was given to the elements of dosimetry and treatment planning that would be needed to carry out the pilot study of proton therapy. Because the added cost is expected to be several thousand dollars per patient in the first year and because justifying that much cost will require an attempt at improving cure rates, the choice was made to attempt arrangements at a facility offering proton ranges of at least $10 \mathrm{~cm}$. Apparently, the isodose plots of cases where $65 \mathrm{MeV}$ protons covered the tumor target precisely, such as Fig. 4 and 5, did not offer significant therapy advantage over the isodose plots for megavoltage electrons. At least there was insufficient advantage to warrant the extra expense of taking patients outside of the present department facility for treatment.

Further discussion revolved around beam monitoring procedures. Requests for technical advice from the ORIC staff seem likely to arise and to be well received.

The decision was also made to press for a cooperative arrangement involving a resident radiotherapist and a satisfactory referral system for the selected patients. Such a pilot study when successful would become a significant part of the clinical training for effective radiotherapy at several proton facilities that are very likely to have useful beams available in the next few years.

\section{CONCLUDING COMMENTS}

The criclcal need in a pilot study that seeks to establish some of the clinical advantages of the improved dose distribution available in proton therapy is for the referral of an adequate number of curable patients, say from ten to a hundred in the first year. They need not all have the same tumor type but they should be staged as curable or be in the early stages of those types for which the present cure rates are very low. Patients with carcinoma of the pancreas should be considered. Staging should be uniform and therefore involve the same team of radiotherapists. With this supply of patients included in the study, additional patients in later stages could also be included if the funds were available.

Private funding is the most likely source of monetary support for the first year or so of the study. An active role of a resident therapist at the proton facility is absolutely vital to the progress of the proposed pilot study of proton therapy. 


\section{ACKNOWLEDGEMENTS}

The authors wish to express their gratitude to the staff of the ORIC whose aid not only made the summer fruitful but whose humor made the season too short. Our special thanks go to J. A. Martin whose interest and active support made the study possible. One of us (JGC) was privileged to atterd the BNL Summer Study on.Proton Therapy and wishes to acknowledge his debt to the BNL Accelerator Department and the Associated Univerșities' hosts. 


\section{REFERENCES}

1. A review of detection methods in use in Sweden, including AGA Thermovision, is given by G. Wennstrom in Proc. IEEE 57, No. 11, 1809 (1969).

2. Successful location of certain tumors by sonar mapping is described by D. Briascho (UAB, Dept. of Therapeutic Radiology) in Southern Medical Journal 65, 1331 (Nov. 1972), "Clinfcal Application of Diagnostic Ultrasound in Abdominal Malignancy."

3. Cell survival measurements are reported by $P$. Todd in Science 174, 1127, (December 10, 1971), in Rad. Res. Supp1. 7, 199 (1967), and in the Los Alamos Scientific Laboratory Report LA-4653 MS, April 1971 - copies of which are available from the National Technical Information Service, U.S. Department of Commerce, 5285 Royal Road, Springfield, Va. 22151, printed copy $\$ 3.00$, microfiche $95 \mathrm{c}$.

4. A channel for delivering negative pions to cancer patients is being developed by H. A. Schwettman and M. Bagshaw and co-workers at Stanford University Medical Center.

5. A clinical study of pion therapy by M. Kligerman and L. Rosen and co-workers is underway at the Los Alamos Scientific Laboratory LAMPF .

6. Heavy ion irradiation studies at the Princeton Particle Accelerator have been terminated; some results are described in a series of articles in Science 174, 1121-1127 (December 10, 1971).

7. Heavy ion irradiation studies are continuing at the Lawrence Berkeley Laboratories; preliminary results are described in Science 174, 1128-1133 (December 10, 1971).

8. M. L. M. Boone and A. Wiley, Jr., IEEE Trans. Nuc1. Sci. NS $-18 \underline{3}$, 36 (1971).

9. M. Raju, "Negative Pion Beams for Radiotherapy" in the'Proceedings of the Symposium on Pion and Proton Radiotherapy, held December 4, 1971, at the National Accelerator Laboratory, Batavia, Illinois, 'T. L. Collins, Symposium Chairman.

10. W. H. Bragg and W. Klienman, Proc. Roy Soc. (1904).

11. A. M. Koehler in a paper entitled "Use of Protons for Radiotherapy" in the Proceedings of the Symposium on Pion and Proton Radiotherapy, held December 4, 1971 at NAL, Batavia, Illinois, T.L. Collins, Symposium Chairman.

12. A review was given by J. Archambeau, for the BNL Summer Study of Proton Radiotherapy, V. P. Bond, Study Chairman. 
13. E. B. Darden, Jr., K. W. Christenberry, J. J. Beauchamp, R. S. Bender, M. C. Jernigan, J. W. Conklin and A. C. Upton, Rad. Res. 43 , 598 (1970).

14. R. R. Wilson, Radiology 47, 487 (1946).

15. R. S. Bender and E. B. Darden, Jr., Rad. Res. 41, 247-258 (1970).

16. R. S. Bender et al., in the section labeled "Annual Progress Report of the Electronuclear Division," ORNL, 1967, 101-102.

17. A. M. Koehler, Accelerator Dept. Seminar, BNL; August 10, 1972.

18. J. F. Janni, Calculations of energy loss, range, path-length straggling, multiple scattering, and the probability of inelastic nuclear collisions for $0 / 1$ to $1000 \mathrm{MeV}$ protons, Air Force Weapons Technical Report, AFWL-TR-65-150, Kirtland AFB, New Mexico (1966).

19. Neutron yields have been calculated by H. W. Bertini, ORNL-3383 (1963).

20. Neutron yields have been measured for $190 \mathrm{MeV}$ protons in various metals by E. E. Gross, UCRL-3330 (1957) and UCRL-3337. A summary is given in the Yale Physics Dept. Report Y-12, entitled "The Design of a Very High Intensity Proton Linear Accelerator as a Meson Factory at an Energy of $750 \mathrm{MeV}$," dated October 1964.

21. W. Preston and A. Koehler, "Diffusion Effects with Small Diameter Proton Beams in Water," Report on the Biomedical Project at the Harvard Cyclotron, unpublished.

22. Cf. C. A. Tobias, H. Ariger; and J": Lärence, Am. H. J. Roenthenol; Rad. Therapy and Nuclear Med. 67, 1 (1952).

23. S. Stenson in the paper entitled "Clinical Experience with Proton Beams" in the Proceedings of the Symposium on Pion and Proton Radiotherapy held at NAL, Batavia, Illinois on December 4, 1971.

24. H. Kim, P. Todd, and Martins, a current study of OER in the Braggpeak of alpha particles.

25. The computer display of ultrasound anatomical outlines obtained by sequential scans of a section of the patient by a single sonar channel under the direction of D. J. Brascho, M.D., at the UAB Mediral Center is described in "A New Ultrasound Option," P-C-Gram 2, available from Artronix, 716 Hanley Industrial Court, St. Louis, MO 63144. 
Table I. DOSE DELIVERED TO MUSCLE TISSUE BY A WIDE BEAM OF 65 MeV PROTONS.

Modified depth dose distribution calculated by adding to the unmodified Bragg-peak distribution of column 2, four distributions with relative intensities of $.4, .33, .250, .22$, and water equivalent absorber thicknesses of $3 \mathrm{~mm}, 6 \mathrm{~mm}, 9 \mathrm{~mm}$, and $12 \mathrm{~mm}$, respectively.

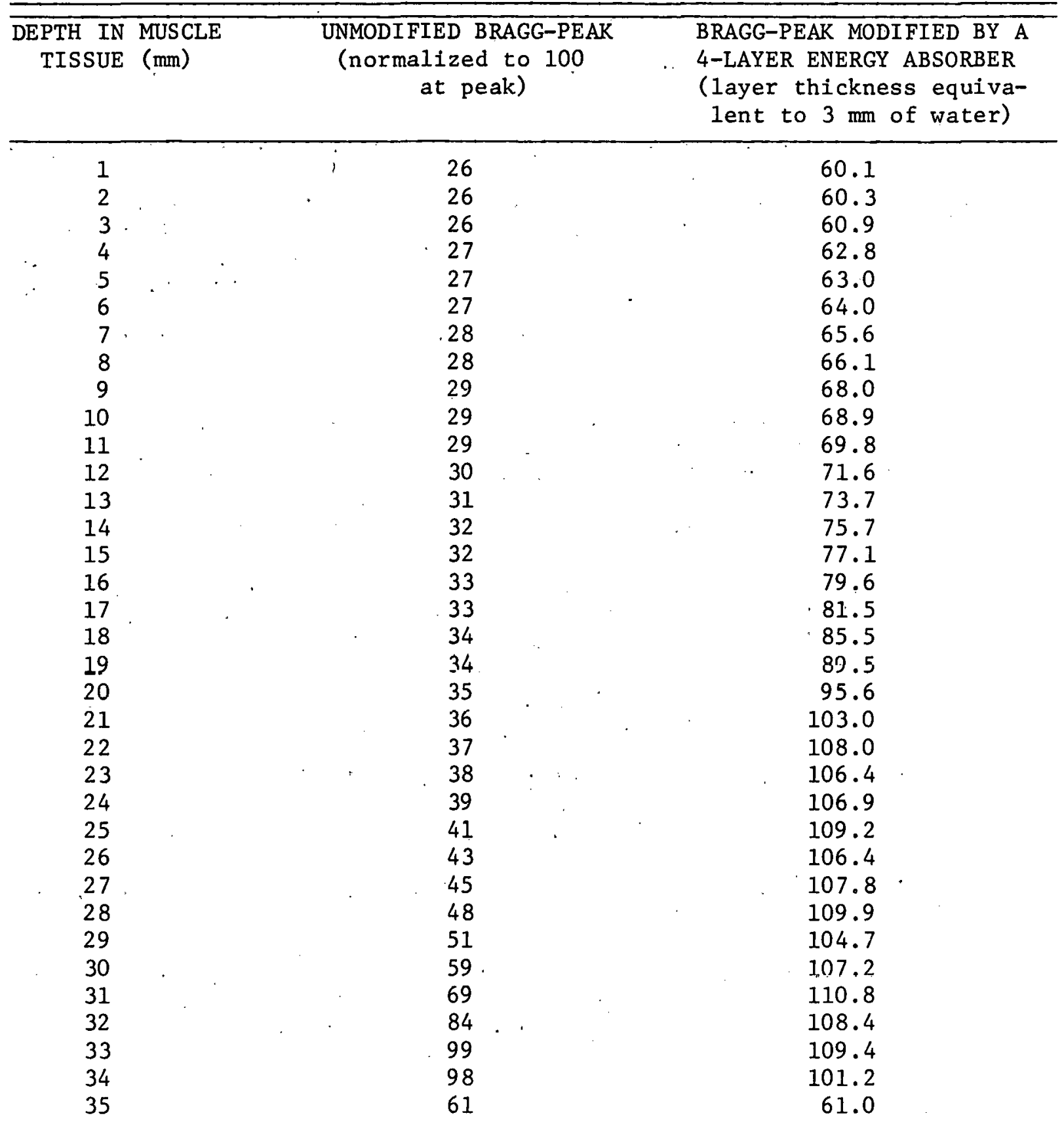


TABLE II. DOSE DELIVERED TO MUSCLE TISSUE BY A WIDE BEAM OF $130 \mathrm{MeV}$ PROTONS

Modified depth dose distribution calculated by adding to the unmodified Bragg-peak distribution of column 2, four distributions with relative intensities of $.345,210,140$, and 100 with : water equivalent absorber thicknesses of $8 \mathrm{~mm}, 14 \mathrm{~mm}$, $20 \mathrm{~mm}$, and $26 \mathrm{~mm}$, respectively.

\begin{tabular}{|c|c|c|c|}
\hline $\begin{array}{l}\text { DEPTH IN } \\
\text { TISSUE }\end{array}$ & $\begin{array}{l}\text { MUSCLE } \\
(\mathrm{mm})\end{array}$ & $\begin{array}{c}\text { UNMODIFIED BRAGG-PEAK } \\
\text { (normalized to } 100 \\
\text { at peak) }\end{array}$ & $\begin{array}{l}\text { BRAGG-PEAK MODIFIED BY A } \\
\text { 4-LAYER ENERGY ABSORBER }\end{array}$ \\
\hline 0 & & 33.0 & 59.6 \\
\hline 5 & & 33.1 & 59.8 \\
\hline 10 & & 33.2 & 60.0 \\
\hline 15 & & 33.4 & 60.4 \\
\hline 20 & & 33.6 & 60.8 \\
\hline 25 & & 33.8 & 61.2 \\
\hline 30 & & 34.0 & 61.7 \\
\hline 35 & & 34.2 & 62.3 \\
\hline 40 & & 34.4 & 62.9 \\
\hline 45 & & 34.9 & 63.9 \\
\hline 50 & & 35.4 & 65.0 \\
\hline 55 & & 35.9 & 66.3 \\
\hline 60 & & 36.4 & 67.8 \\
\hline 65 & & 37.3 & 69.8 \\
\hline .70 & & 38.3 & 72.1 \\
\hline 75 & & 39.5 & 74.8 \\
\hline 80 & & 41.0 & 78.2 \\
\hline 85 & & 42.7 & 82.6 \\
\hline 90 & & 44.7 & 90.0 \\
\hline 95 & & 46.6 & 96.8 \\
\hline 96 & & 47.0 & 96.6 \\
\hline 97 & & 47.6 & 96.4 \\
\hline 98 & & 48.2 & 97.4 \\
\hline 99 & & 48.8 & 98.9 \\
\hline 100 & & 49.4 & 100.4 \\
\hline 101 & & 50.0 & 99.9 \\
\hline 102 & & 50.9 & 99.4 \\
\hline 103 & & 51.8 & 98.8 \\
\hline 104 & & 52.7 & 100.1 \\
\hline .105 & & 53.6 & 101.6 \\
\hline 106 & & 54.5 & 103.7 \\
\hline 107 & & 56.0 & 102.8 \\
\hline 108 & & 57.5 & 101.4 \\
\hline 109 & & 59.0 & 100.0 \\
\hline 110 & & 61.0 & 100.4 \\
\hline 111 & & 62.5 & 100.1 \\
\hline 112 & & 67.0 & 102.2 \\
\hline
\end{tabular}


Table II (continued):

\begin{tabular}{ccc}
\hline $\begin{array}{c}\text { DEPTH IN MUSCLE } \\
\text { TISSUE (mm) }\end{array}$ & $\begin{array}{c}\text { UNMODIFIED BRAGG-PEAK } \\
\text { (normalized to } \begin{array}{c}\text { Bon } \\
\text { at peak) }\end{array}\end{array}$ & $\begin{array}{c}\text { BRAGG-PEAK MODIFIED BY A } \\
\text { 4-LAYER ENERGY ABSORBER }\end{array}$ \\
\hline & 72.5 & 101.1 \\
113 & 80.0 & 101.1 \\
114 & 85.0 & 98.8 \\
115 & 90.0 & 98.6 \\
117 & 94.5 & 99.6 \\
118 & 99.0 & 102.4 \\
119 & 99.9 & 101.6 \\
120 & 96.0 & 96.7 \\
122 & 60.0 & 60.0 \\
124 & 25.0 & 25.0 \\
126 & 10.0 & 10.0 \\
128 & 02.0 & 02.0 \\
130 & 00.0 & 00.0 \\
& & \\
\hline
\end{tabular}


FIGURE CAPTIONS

Fig. 1 - Responses to Cobalt $\gamma$ rays. Courtesy of Boone and Wiley, reference 8 , as cited by Raju, reference 9 .

Fig. 2 - Distribution of Proton Beam as Expanded

Fig. 3 - Isodose Plots of a Head Section for Carclnoma of the Tonsil. Scale is $1: 2$. Contours in a) show treatment with ${ }^{60} \mathrm{Co}$. Contours in b) show the improved dose distribution obtainable with $65 \mathrm{MeV}$ protons and the 4-layer rotating absorber as listed in Table $I$.

Fig. 4 - Computer printed isodose plot showing the proton dose distribution. The edge of the maximum dose region is indicated by "9's". The $75 \%$ contour is indicated by " 1 's". The scale is $1: 1$. Anatomical information is indicated by the following scheme: " $S$ " indicates skin tissue; " 0 " indicates bone or radiosensitive tissue, " $\mathrm{X}$ " indicates the edge of a tumor mass.

Fig. 5 - Computer printed 1sodose plot of a carcinoma of the inner ear. The edge of the maximum dose region is indicated by " 9 's". The $80 \%$ contour is indicated by " 8 's". The $10 \%$ contour is indicated by " 1 's". Anatomy information is indicated by the same scheme as in Fig. 4. As a first approximation to the spaces in the outer ear, the line of dots was taken as the effective edge of.tissue.

Fig. 6 - Computer printed isodose plot of a carcinoma of the inner ear. Scale is $1: 1$. The edge of the maximum dose region is indicated by "9's". The $80 \%$ contour is indicated by " 8 's". The $10 \%$ contour is indicated by " 1 's". Anatomy, information, indicated by the same scheme. as in.Fig. 4, was obtained directly from a sonlar map reported by Brascho in reference 2 . 


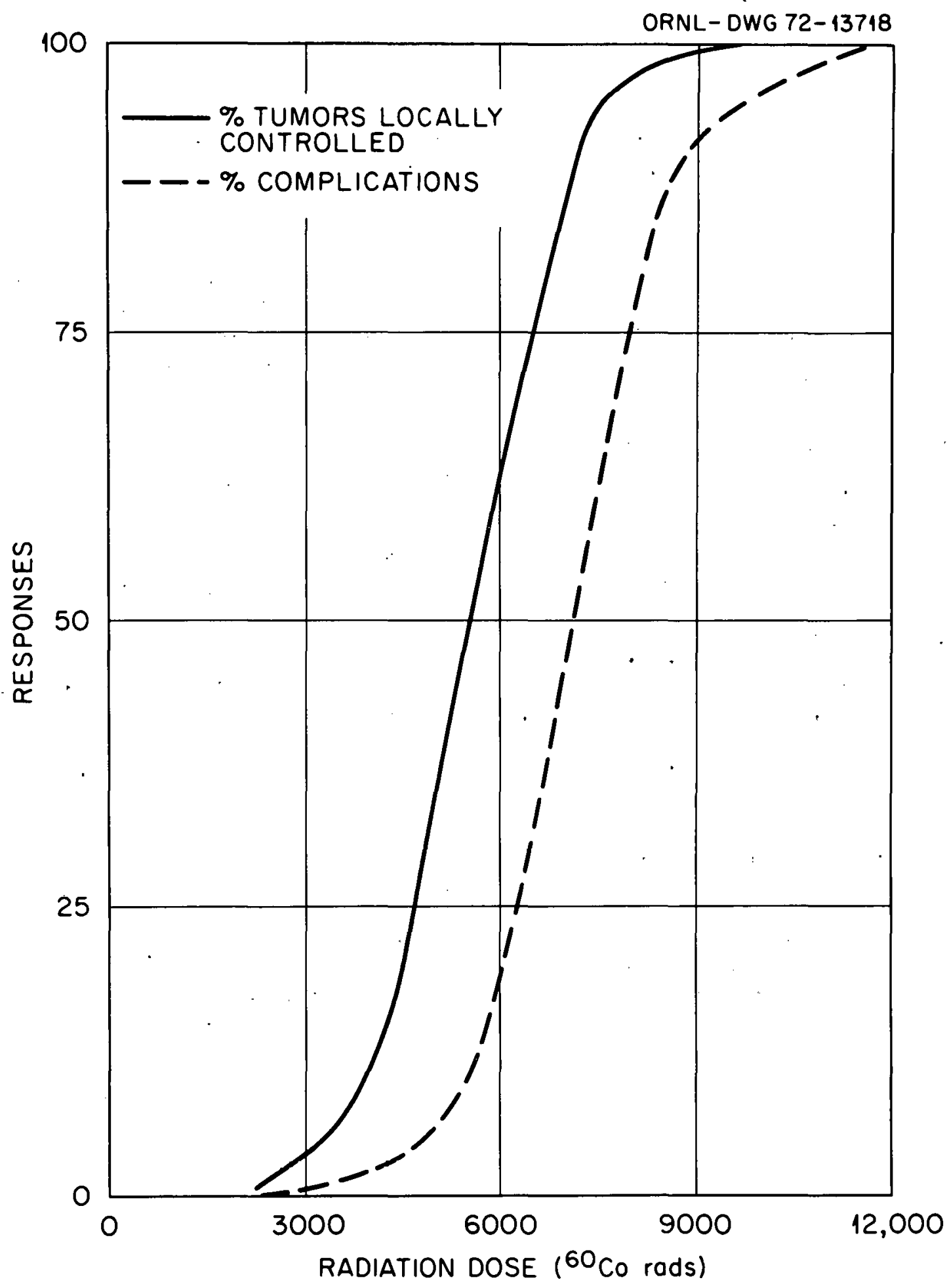

Fig. 1 


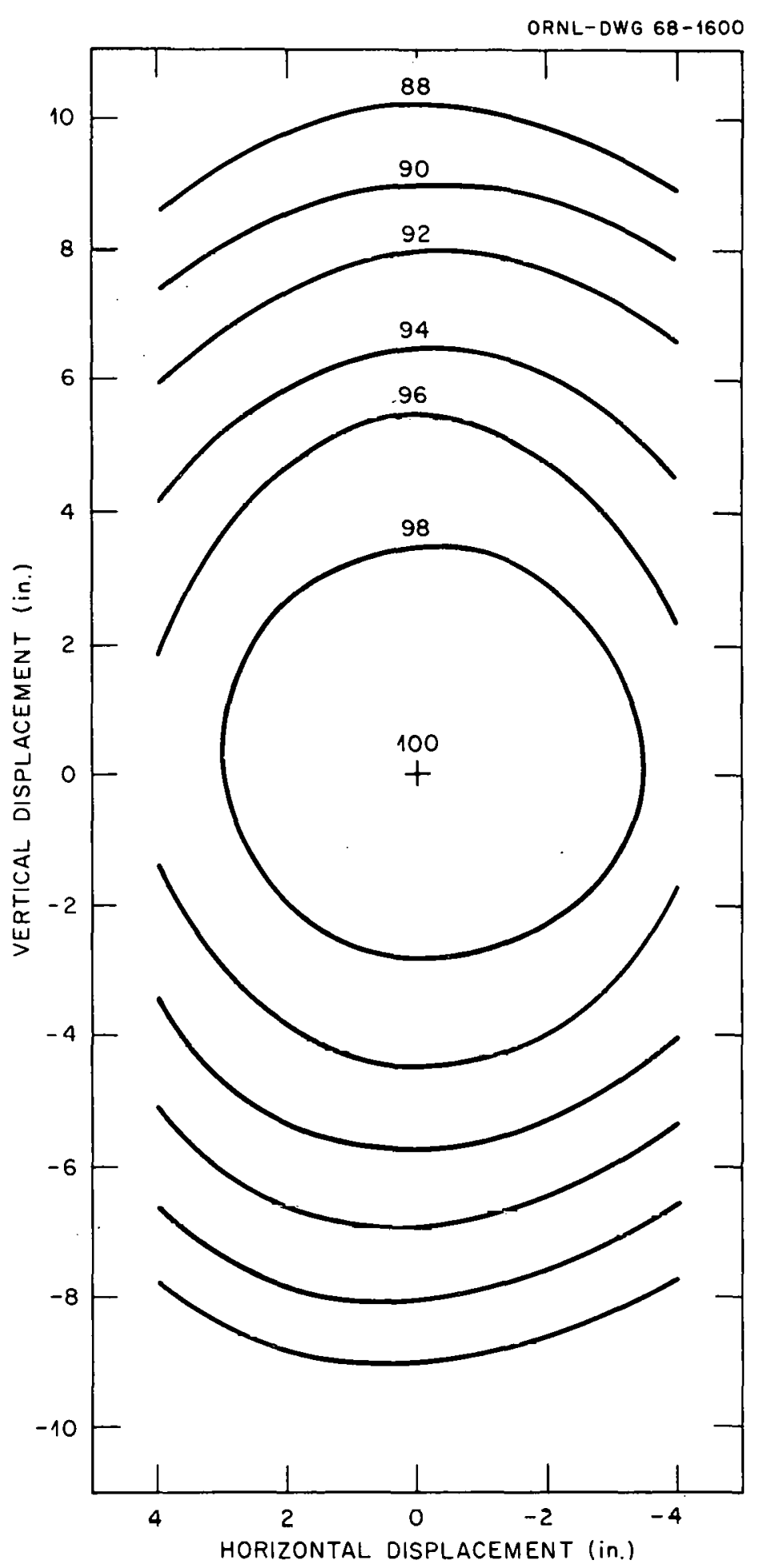

Fig. 2 


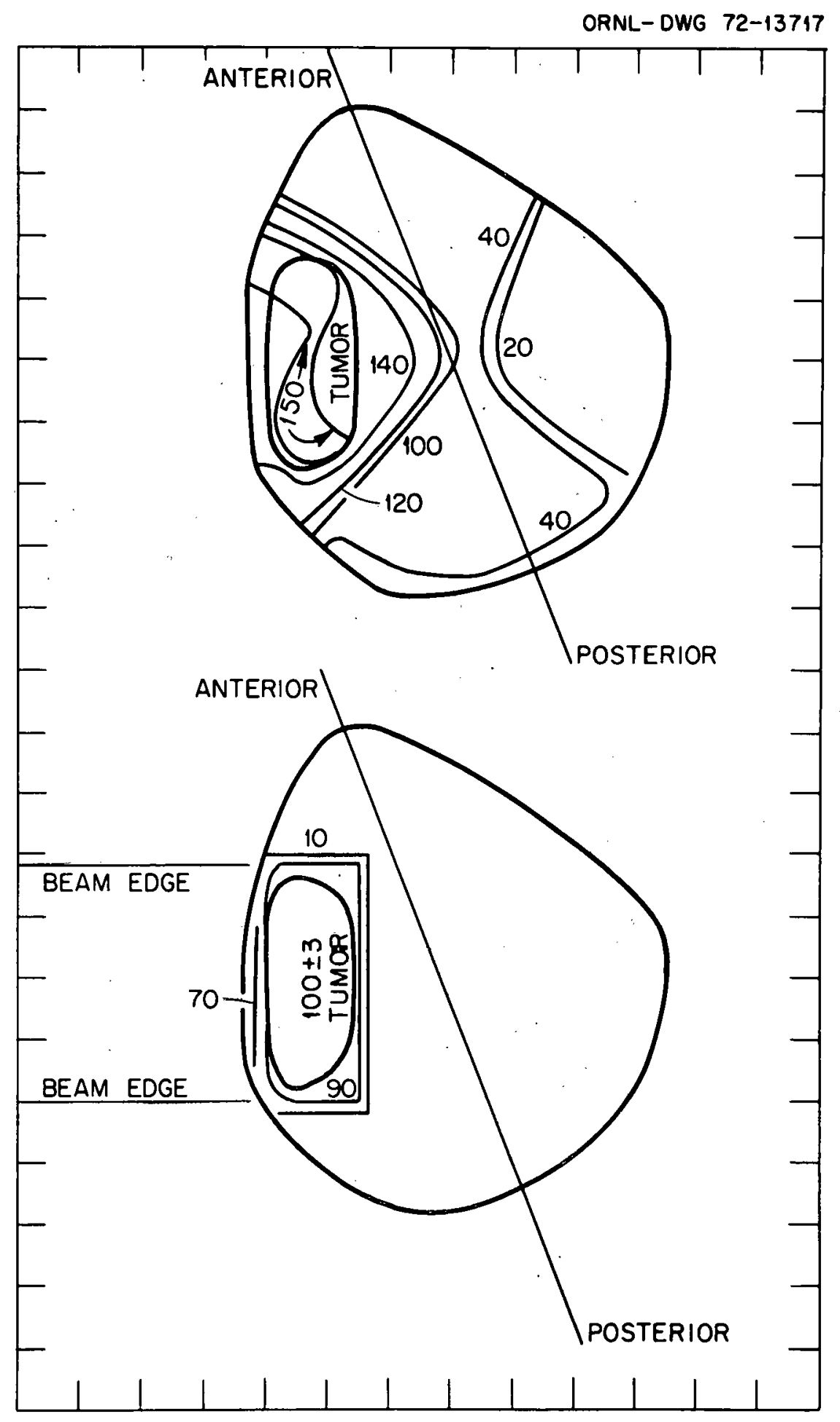

Fig. 3 


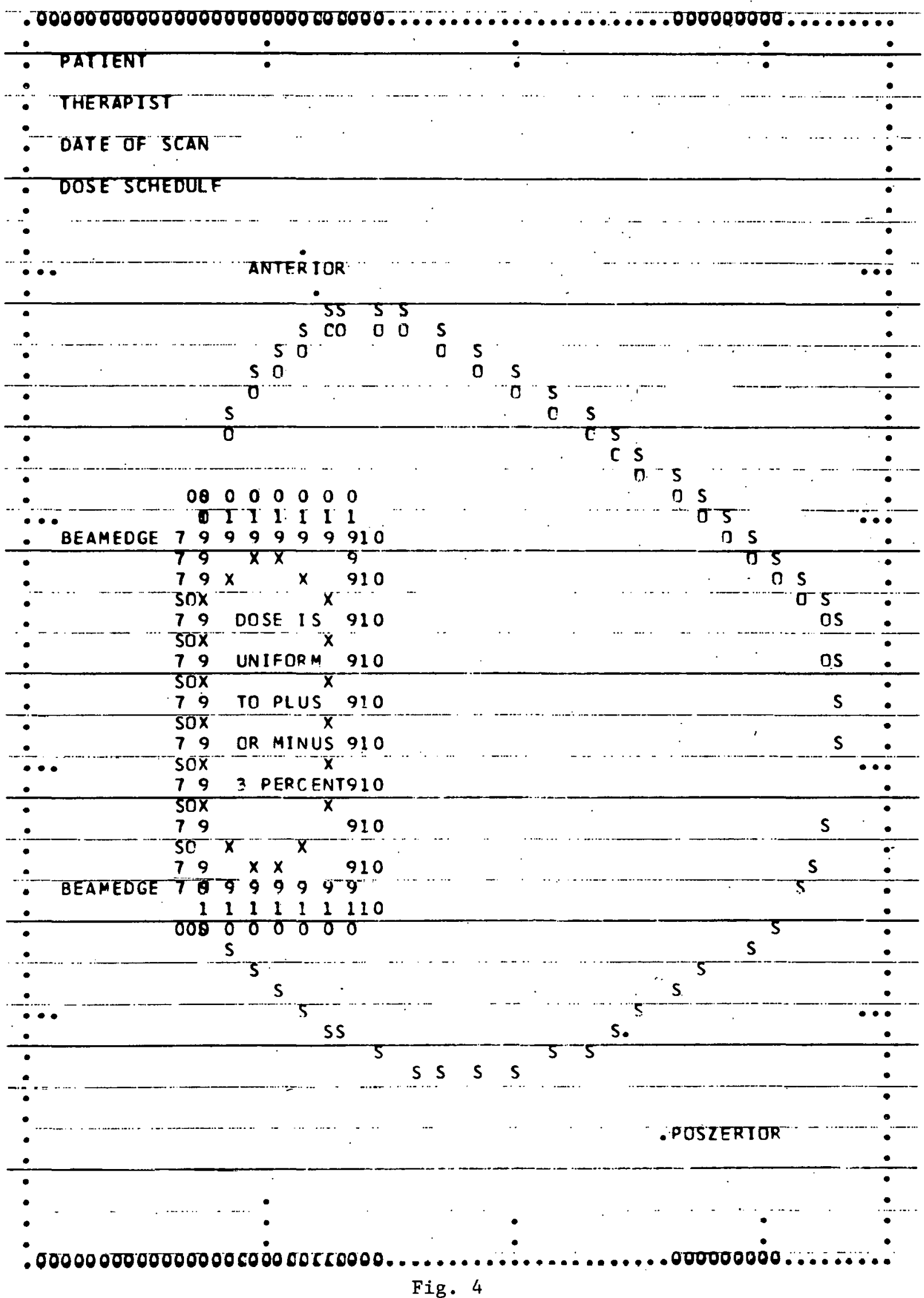




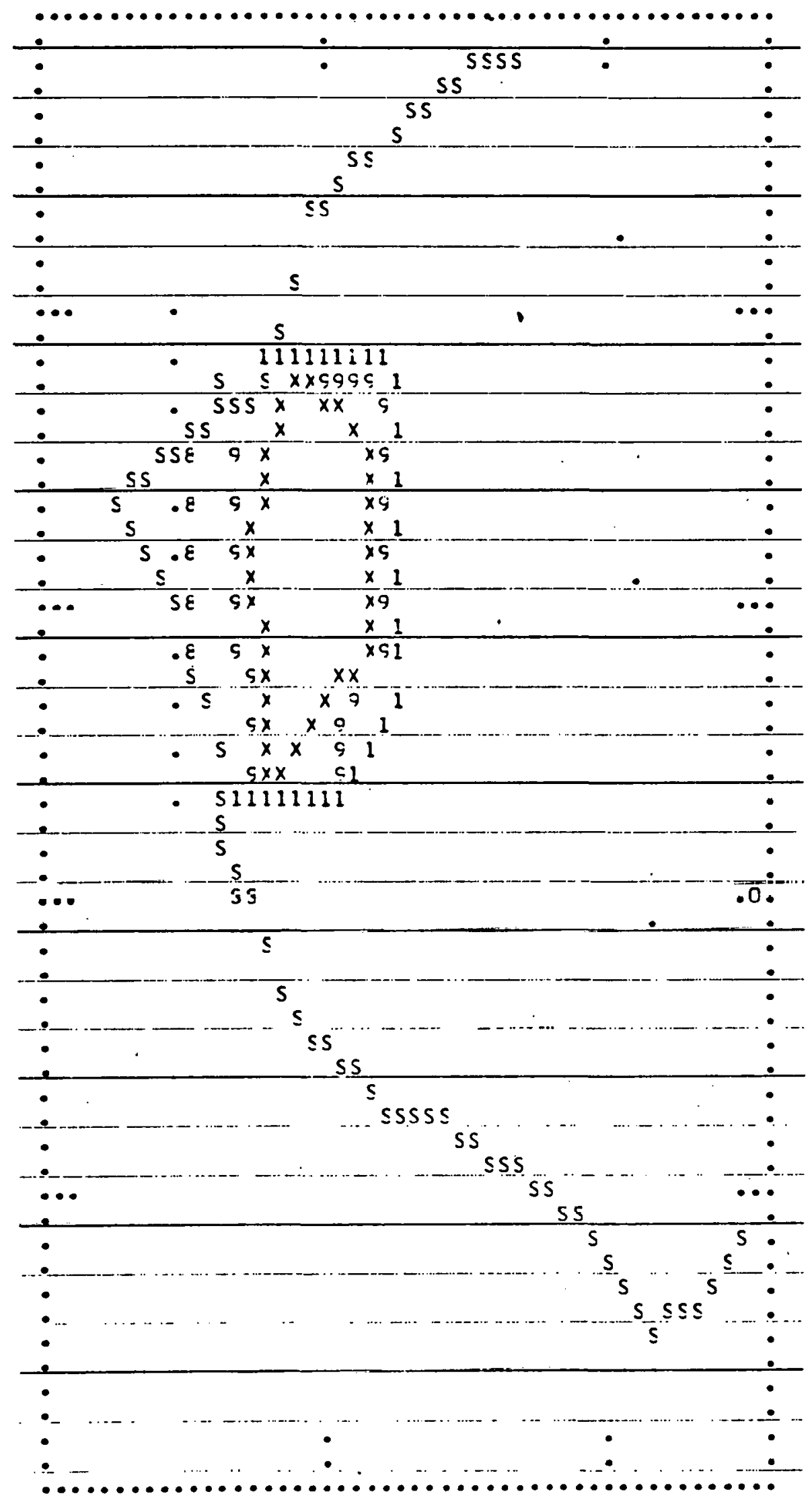

Fig. 5 


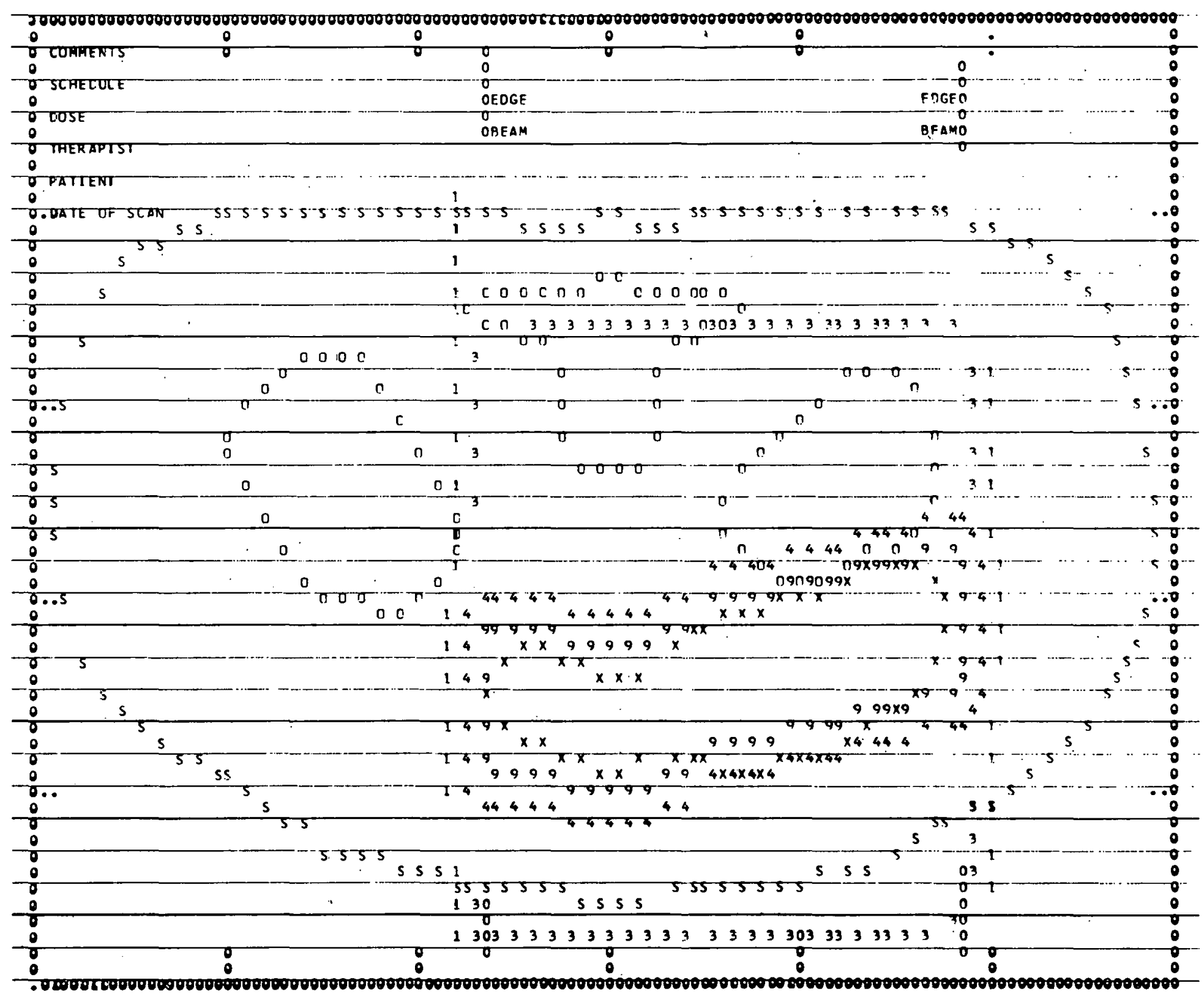

Fig. 6 
THIS PAGE

WAS INTENTIONALLY

LEFT BLANK 


\section{INTERNAL DISTRIBUTION}

1. H. I. Adler

2. J. B. Ball

3. F. L. Culler

4. E. B. Darden

5. J. L. C. Ford

6. J. L. Fowler.

7. C. B. Fulmer

8. C. D. Goodman

9. E. E. Gross

10. M. L. Halbert

11. D. C. Hensley

12. E. D. Hudson

13. C. M. Jones

14. 0. L. Keller

15. B. H. Ketelle

16. R. S. Livingston

17. R. S. Lord

18. C. A. Ludemann

19. M. L. Mallory
20. J. A. Martin

21. E. Newman

22. R. W. Peelie

23. F. Plasil

24. R. L. Robinson

25. M. J. Saltmarsh

26. H. W. Schmitt

27. S. Siegel

28. R. J. Silva

29. A. H. Snel1

30. P. H. Stelson

31. K. S. Toth

32. J. R. Totter

33. A. M. Weinberg

34. A. Zucker

35-36. Central Research Library

37. Document Reference Section

38-40. Laboratory Records Department

\section{EXTERNAL DISTRIBUTION}

41-42. Technical Information Center, OR

43. Research and Technical Support Division, ORO

44. W. O. Archambeau, M.D., Nassau County Medical Center, East Meadow, New York

45. A. C. L. Barnard, Dept. of Physics, University of Alabama, Birmingham, Alabama

46. R. P. Bauman, Dept. of Physics, University of Alabama, Birmingham, Alabama

47. G. W. Bennett, Brookhaven National Laboratory, Upton, New York

48. B. E. Blackburn, Dept. of Therapeutic Radiology, University Hospital, Birmingham, Alabama

49. Donn J. Brascho, M.D., Dept. of Therapeutic Radiology, University Hospital, Birmingham, Alabama

50-52. J. G. Castle, University of Alạama, Birmingham, Alabama

53. Maxie L. Davis, M.D., Dept. of Therapeutic Radiology, University Hospital, Birmingham, Alabama

54-55. R. B. Dickinson, University of California, Berkeley, California

56. Melvin Griem, M.D., Dept. of Radiotherapy, University of Chicago Medical Center, Chicago, Illinois

57. M. M. Kligerman, M.D., Dept. of Radiotherapy, University of Mexico Medical Center, Albuquerque, New Mex1co

58. A. M. Koehler, Cyclotron Laboratory, Harvard University, Cambridge, Massachusetts

59. Arvid Lundy, LAMPF, Los Alamos Scientific Laboratory, Los Alamos, New Mexico 


\section{EXTERNAL DISTRIBUTION (contd.)}

60. C. A. Pearson, Dept: of Physics, University of Alabama, Birmingham, Alabama

61. W. E. Powers, M.D., Dept. of Radiotherapy, Washington University Hospital, St. Louis, Missouri

62. E. L. Robinson, Dept. of Physics, University of Alabama, Birmingham, Alabama

63. R. E. Roth, M.D., Dept. of Therapeutic Radiology, University Hospital, Birmingham, Alabama

64. Paul. Todd, Dept. of Blophysics, Pennsylvania State University, University Park, Pennsylvania

65. A. van der Woude, Kernfysisch Versneller Instituut, Universiteitscomplex Paddepoel, Groningen, The Netherlands 